\title{
GENETIC RELATIONSHIPS AMONG SEROGROUP B: SEROTYPE 4 Neisseria meningitidis STRAINS
}

\begin{abstract}
SUMMARY
We compared the results obtained by serotyping of PorB epitopes using an expanded panel of monoclonal antibodies (mAb) including $\mathrm{mAb} 7$ and $\mathrm{mAb} 10$, with results obtained by RFLP of rRNA genes (ribotyping). The purpose of this study was to assess the correlation between phenotypic- and genotypic- methods for typing $N$. meningitidis. The ribotypes obtained using ClaI or EcoRV endonucleases grouped the strains in seven and two different patterns, respectively. This additional characterization of PorB epitopes improved the correlation between these two methods of typing $N$. meningitidis.
\end{abstract}

KEYWORDS: Neisseria meningitidis; Serogroup B; Serotype 4; Ribotyping; Strain differentiation.

\section{INTRODUCTION}

Meningococcal disease (MD) has been a significant cause of mortality and morbidity throughout the world, particularly in Brazil ${ }^{9,10,11}$. Characterization of meningococcal strains has been based on antigenic differences in the capsule (serogroup), the four variable regions (VRs) of the PorB outer membrane protein (OMP) (serotype), and the two VRs of the PorA OMP (serosubtype) $2,4,6,7,8,12,13,16,18$. Serological typing of PorB epitopes has been shown to be the useful method for epidemiological characterization of large numbers of $N$. meningitidis strains. Serotype-defining monoclonal antibodies (mAbs) react with peptide epitopes located in the PorB VR loops ${ }^{12,15}$. Serologic results can be useful for predicting the potential efficacy of vaccines, especially for serogroup B strains.

In Greater São Paulo, Brazil, from 1990 through 1998, serogroup B, serotype 4 (B:4) strains have accounted for approximately $80 \%$ of patient isolates ${ }^{9,11}$. Previous studies have shown that by restriction fragment length polymorphism of rRNA genes (ribotyping) among B:4 strains, the most frequent pattern obtained was referred to as Rb1. Many of these B:4 Rb1 strains were also serosubtype P1.15 (60\%) ${ }^{11}$; therefore, strains with the phenotype B:4:P1.15 have been considered part of the genotype $\mathrm{Rb} 1$ and responsible for the actual epidemic situation in that region.

Meningococcal serological classification has historically suffered from the deficiency that groupings defined by serotyping or serosubtyping may contain strains that are genetically dissimilar. In addition, the current panel of mAbs used for serotyping underestimates PorB variability by at least $50 \%$ because reagents for several major PorB variable region families do not exist ${ }^{12}$. This difficulty, also reported for serosubtyping based on the PorA protein, is in part responsible for the inconsistent results between serological and molecular analyses, leading to inaccurate strain identification and incomplete epidemiological data.

Refinements in serologic typing methods have been evaluated to improve their specificity. Recently, the number of serotype-defining mAbs was expanded by three new mAbs 7,10 and $19^{12}$ that recognize previously uncharacterized PorB outer membrane epitopes, improving the sensitivity of serotyping. The mAb 7 and mAb 10 were recently used to characterize a small number of Brazilian B:4 strains ${ }^{12}$. Each of the four variable regions of the PorB protein may now be assessed for $\mathrm{mAb}$ reactivity and characterized in an unknown isolate, thus resolving a number of formerly non-serotypeable strains.

In this study, we used Brazilian B:4 N. meningitidis strains isolated in 1997 to assess the correlation between phenotype-based and genotypebased methods of typing meningococci. We compared the results obtained by serotyping using an expanded mAb panel, including $\mathrm{mAb} 7$ and $\mathrm{mAb}$ 10 , with the results obtained by ribotyping. The purpose of this study was to verify whether the characterization of multiple PorB VR epitopes in the same isolate help to differentiate distinct clonal lines of B:4 meningococcal strains.

\section{MATERIALS AND METHODS}

Neisseria strains and serological typing. During 1997, $630 \mathrm{~N}$. meningitidis serogroup B strains were recovered from patients with

(1) Division of Medical Biology, Bacteriology Department, Adolfo Lutz Institute, São Paulo, SP, Brazil.

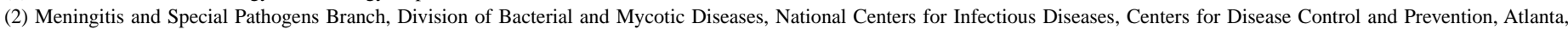
Georgia, USA.

Correspondence to: Ana Paula S. Lemos, Instituto Adolfo Lutz, Seção de Bacteriologia, Av. Dr. Arnaldo 351, 01246-902 São Paulo, SP, Brazil. e-mail: apaula@ial.sp.gov.br 
systemic disease in different states or cities in Brazil. The serotypes and serosubtypes of these strains are presented in Table 1. These strains have been serotyped and serosubtyped by dot blotting of whole cell suspensions ${ }^{17}$ using an expanded panel of mAbs including, $\mathrm{mAb} 7$ and $\mathrm{mAb} 10$ described previously ${ }^{12}$. We selected 105 strains, 93 of which express epitope 4 on the PorB protein, representing the phenotypes B:4 $(n=1), \mathrm{B}: 4,1(n=1)$, $\mathrm{B}: 4,7(n=70), \mathrm{B}: 4,10(n=20)$, and B:4,21 $(n=1)$ for further study. The $\mathrm{B}: 4,7$ group of strains includes the phenotypes $\mathrm{B}: 4,7: \mathrm{P} 1.7,1(n=8)$ and $\mathrm{B}: 4,7: \mathrm{P} 1.15(n=45)$. A number of these strains were randomly selected to represent approximately $10 \%$ of each of the major phenotypes isolated during 1997 (serotype plus serosubtype). All other strains selected for this study represent the total of strains for each phenotype isolated in the same period. We also included in this study seven non-serotype 4 strains expressing epitopes $7,(\mathrm{~B}: 7, n=6)$ or 10 , (B:10, $n=1)$, two epidemic strains of $N$. meningitidis B:4 isolated in Brazil during 1988 and 1989, N.150/88 and N.44/89; and three other species of Neisseria ( N. sicca, $N$. cinereae, and $N$. polysacchareae as out group). The characteristics of the 105 strains are presented in Table 2.

Ribotyping. Ribotype was determined as described previously ${ }^{14} . \mathrm{N}$. meningitidis DNA was digested with $C l a \mathrm{I}$ or $E c o \mathrm{RV}^{10}$. The pKK3535 plasmid DNA was used as a probe ${ }^{1}$. Strains with identical patterns were given the same banding pattern number. When banding pattern numbers for the two restriction endonucleases were combined, each unique pattern group was designated a separate ribotype and was given a letter of the alphabet. The characteristics of all 105 strains analyzed by ribotyping are presented in Table 2.

Genetic distance. The genetic distance was determined as described previously ${ }^{10}$. The distance between pairs of isolates was calculated by determining the total number of unique bands produced by each restriction endonuclease as a set of bands of decreasing size. Phylogenetic analysis was based on distance matrix output generated by PHYLIP version 3.4 Dollop program.

porB gene and porA variable region analysis. To further investigate the PorB VR types of eight strains representing uncommon phenotypes, we sequenced the porB gene of one B:4; six B:7; and one B:10 strains (Table 3). Primers NMP27 and NMP28 were used to amplify the porB gene of those strains and 14 primers previously described were used to sequence the $\operatorname{por} B$ gene ${ }^{12}$. The porA VR nucleotide sequences were determined for nine meningococcal strains non serosubtypeable to evaluate the correlation between the phenotypes B:4,7 and P1.15 (Table 4). Only two regions of porA gene, that include VR1 and VR2, were sequenced for these strains. Two primers for each region were used (one forward and one reverse) designed to be complementary to conserved

Table 1

Distribution of serotypes and serosubtypes among N. meningitidis serogroup B isolated in Brazil during $1997(n=630)$

\begin{tabular}{|c|c|c|c|c|c|c|c|c|c|c|c|c|c|c|c|c|}
\hline \multirow{3}{*}{ Serosubtypes } & \multicolumn{16}{|c|}{ Serotypes } \\
\hline & \multicolumn{2}{|c|}{4} & \multicolumn{2}{|c|}{4,1} & \multicolumn{2}{|c|}{4,7} & \multicolumn{2}{|c|}{4,10} & \multicolumn{2}{|c|}{4,21} & \multicolumn{2}{|c|}{7} & \multicolumn{2}{|c|}{10} & \multicolumn{2}{|c|}{ Others } \\
\hline & $n$ & $\%$ & $n$ & $\%$ & $n$ & $\%$ & $n$ & $\%$ & $n$ & $\%$ & $n$ & $\%$ & $n$ & $\%$ & $n$ & $\%$ \\
\hline P1.1 & - & - & - & - & 1 & 0.16 & - & - & - & - & - & - & - & - & - & - \\
\hline P1.3 & 1 & 0.16 & - & - & 6 & 0.95 & - & - & - & - & 1 & 0.16 & - & - & 3 & 0.48 \\
\hline $\mathrm{P} 1.5,2$ & - & - & - & - & - & - & 1 & 0.16 & - & - & - & - & - & - & - & - \\
\hline $\mathrm{P} 1.7,1$ & - & - & - & - & 70 & 11.11 & - & - & - & - & - & - & - & - & 2 & 0.32 \\
\hline P1.7,16 & - & - & - & - & 1 & 0.16 & - & - & - & - & - & - & - & - & 20 & 3.17 \\
\hline P1.9 & - & - & 1 & 0.16 & 1 & 0.16 & 11 & 1.73 & 1 & 0.16 & - & - & - & - & 9 & 1.43 \\
\hline $\mathrm{P} 1.12,13$ & - & - & - & - & - & - & 2 & 0.32 & - & - & - & - & - & - & - & - \\
\hline P1.14 & - & - & - & - & - & - & 2 & 0.32 & - & - & - & - & - & - & 1 & 0.16 \\
\hline P1.15 & - & - & - & - & 402 & 63.81 & 3 & 0.48 & - & - & 5 & 0.79 & - & - & 22 & 3.49 \\
\hline $\mathrm{P} 1.22 \mathrm{a}, 14$ & - & - & - & - & 1 & 0.16 & - & - & - & - & - & - & - & - & 15 & 2.38 \\
\hline nt & - & - & - & - & 7 & 1.11 & 1 & 0.16 & - & - & - & - & 1 & 0.16 & 16 & 2.54 \\
\hline Others & - & - & - & - & - & - & - & - & - & - & - & - & - & - & 23 & 3.65 \\
\hline Total & 1 & 0.16 & 1 & 0.16 & 489 & 77.62 & 20 & 3.17 & 1 & 0.16 & 6 & 0.95 & 1 & 0.16 & 111 & 17.62 \\
\hline
\end{tabular}


Table 2

Characteristics of the 105 Neisseria strains used in this study

\begin{tabular}{|c|c|c|c|c|c|c|}
\hline & \multirow[b]{2}{*}{$\begin{array}{l}\text { Number } \\
\text { of isolates }\end{array}$} & \multirow[b]{2}{*}{ Serogroup: Serotype: Subtype } & \multicolumn{2}{|c|}{$\begin{array}{l}\text { Banding pattern } \\
\text { obtained with }^{a}\end{array}$} & \multirow[b]{2}{*}{ Ribotype } & \multirow[b]{2}{*}{ Ribotype Group } \\
\hline & & & Cla $\mathbf{I}$ & EcoRV & & \\
\hline & 1 & B:4:P1.3 & 2 & 1 & $\mathrm{~F}$ & 2 \\
\hline & 1 & $\mathrm{~B}: 4,1: \mathrm{P} 1.9$ & 5 & 1 & $\mathrm{G}$ & $* b$ \\
\hline & 6 & $\mathrm{~B}: 4,7: \mathrm{P} 1.3$ & 2 & 1 & $\mathrm{~F}$ & 2 \\
\hline & 1 & $\mathrm{~B}: 4,7: \mathrm{P} 1.1$ & 1 & 1 & $\mathrm{~A}$ & 2 \\
\hline & 7 & $\mathrm{~B}: 4,7: \mathrm{P} 1.7,1$ & 1 & 1 & $\mathrm{~A}$ & 2 \\
\hline & 1 & $\mathrm{~B}: 4,7: \mathrm{P} 1.7,1$ & 3 & 1 & $\mathrm{~B}$ & 2 \\
\hline & 1 & $\mathrm{~B}: 4,7: \mathrm{P} 1.7,16$ & 1 & 1 & A & 2 \\
\hline & 1 & B:4,7:P1.9 & 1 & 1 & A & 2 \\
\hline & 1 & $\mathrm{~B}: 4,7: \mathrm{P} 1.22 \mathrm{a}, 14$ & 1 & 1 & A & 2 \\
\hline & 45 & $\mathrm{~B}: 4,7: \mathrm{P} 1.15$ & 1 & 1 & A & 2 \\
\hline & 5 & $\mathrm{~B}: 4,7: \mathrm{nt}^{c}$ & 1 & 1 & $\mathrm{~A}$ & 2 \\
\hline & 1 & $\mathrm{~B}: 4,7: \mathrm{nt}$ & 1 & 3 & $\mathrm{E}$ & 2 \\
\hline & 1 & $\mathrm{~B}: 4,7: \mathrm{nt}$ & 7 & 1 & I & 2 \\
\hline & 1 & $\mathrm{~B}: 4,10: \mathrm{P} 1.5,2$ & 4 & 3 & $\mathrm{D}$ & 1 \\
\hline & 11 & B:4,10:P1.9 & 2 & 3 & $\mathrm{C}$ & 1 \\
\hline & 2 & $\mathrm{~B}: 4,10: \mathrm{P} 1.12,13$ & 2 & 3 & $\mathrm{C}$ & 1 \\
\hline & 2 & B:4,10:P1.14 & 2 & 3 & $\mathrm{C}$ & 1 \\
\hline & 3 & $\mathrm{~B}: 4,10: \mathrm{P} 1.15$ & 2 & 3 & $\mathrm{C}$ & 1 \\
\hline & 1 & B:4,10:nt & 2 & 3 & $\mathrm{C}$ & 1 \\
\hline & 1 & $\mathrm{~B}: 4,21: \mathrm{P} 1.9$ & 6 & 1 & $\mathrm{H}$ & $*$ \\
\hline & 1 & B:7:P1.3 & 2 & 1 & $\mathrm{~F}$ & 2 \\
\hline & 5 & $\mathrm{~B}: 7: \mathrm{P} 1.15$ & 1 & 1 & A & 2 \\
\hline & 1 & B:10:nt & 2 & 3 & $\mathrm{C}$ & 1 \\
\hline \multicolumn{7}{|l|}{ Epidemic strains } \\
\hline N.44/89 & 1 & $\mathrm{~B}: 4,7: \mathrm{P} 1.15$ & 1 & 1 & A & 2 \\
\hline N.150/88 & 1 & $\mathrm{~B}: 4,7: \mathrm{P} 1.15$ & 1 & 1 & A & 2 \\
\hline \multicolumn{7}{|l|}{ Out group strains } \\
\hline N. sicca & 1 & - & 8 & 2 & $\mathrm{~J}$ & $*$ \\
\hline N. cinereae & 1 & - & 9 & 4 & $\mathrm{~K}$ & $*$ \\
\hline N. polysacchareae & 1 & - & 10 & 5 & $\mathrm{~L}$ & $*$ \\
\hline
\end{tabular}

$\overline{{ }^{a}}$ Derived as explained in Materials and Methods; ${ }^{b}$ In this study, ribotype group was designed only by ribotypes presented $\geq 85 \%$ identities; ${ }^{c}$ nonserosubtypeable.

Table 3

PorB VR type and ribotype of $N$. meningitidis B:4, B:7 and B:10 strains

\begin{tabular}{|c|c|c|c|c|c|c|}
\hline Strain Number & Serogroup & Serotype & Sero-subtype & PorB VR Type & Ribotype & Accession Number \\
\hline N.61597 & B & 4 & P1.3 & $\underline{4}, \underline{\mathrm{D}}, \underline{7 \mathrm{~b}}, \underline{14 \mathrm{a}}$ & $\mathrm{F}$ & AF060525 \\
\hline N.87097 & B & 7 & $\mathrm{P} 1.15$ & $\underline{4 \mathrm{c}}, \underline{\mathrm{D}}, \underline{7}, \underline{14 \mathrm{~d}}$ & A & AF051531 \\
\hline N.92797 & B & 7 & $\mathrm{P} 1.15$ & $\underline{4 \mathrm{~b}}, \underline{\mathrm{Dc}}, \underline{7,14 \mathrm{a}}$ & A & AF043065 \\
\hline N.5697 & B & 7 & $\mathrm{P} 1.15$ & $\underline{E}, \underline{D}, \underline{7}, \underline{14 a}$ & $\mathrm{~A}$ & AF060526 \\
\hline N.94897 & B & 7 & $\mathrm{P} 1.15$ & $\underline{4 \mathrm{~b}}, \underline{\mathrm{D}}, \mathbf{7}, \underline{14 \mathrm{a}}$ & A & AF060527 \\
\hline N.100397 & B & 7 & $\mathrm{P} 1.15$ & $4 \mathrm{~b}, \mathrm{D}, 7,14 \mathrm{a}$ & A & AF060528 \\
\hline N.103197 & B & 7 & $\mathrm{P} 1.3$ & Del ${ }^{a}$, De, $, \underline{7}, 14 \mathrm{a}$ & $\mathrm{F}$ & AF060529 \\
\hline N.3597 & B & 10 & $\mathrm{nt}$ & $\underline{4 \mathrm{~b}}, \underline{\mathrm{D}}, \underline{10}, 14 \mathrm{a}$ & $\mathrm{C}$ & AF051532 \\
\hline
\end{tabular}

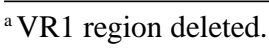


Table 4

PorA VR type and ribotype from nine non serosubtypeable N. meningitidis strains analyzed

\begin{tabular}{lccccc}
\hline $\begin{array}{l}\text { Strain } \\
\text { number }\end{array}$ & Serogroup & Serotype & $\begin{array}{c}\text { Sero- } \\
\text { subtype }\end{array}$ & $\begin{array}{c}\text { PorA } \\
\text { VR Type }\end{array}$ & Ribotype \\
\hline N.3597 & B & 10 & nt & P1. $\underline{\mathrm{Eb}}, \underline{10 \mathrm{a}}$ & $\mathrm{C}$ \\
N.119697 & $\mathrm{B}$ & 4,10 & $\mathrm{nt}$ & $\mathrm{P} 1 . \underline{\mathrm{Eg}}, \underline{\mathrm{A}}$ & $\mathrm{C}$ \\
N.19597 & $\mathrm{B}$ & 4,7 & $\mathrm{nt}$ & $\mathrm{P} 1 . \underline{5 \mathrm{~b}}, \underline{10 \mathrm{i}}$ & $\mathrm{A}$ \\
N.50797 & $\mathrm{B}$ & 4,7 & $\mathrm{nt}$ & $\mathrm{P} 1 . \underline{7 \mathrm{~b}}, \underline{13 \mathrm{a}}$ & $\mathrm{E}$ \\
N.70697 & $\mathrm{B}$ & 4,7 & $\mathrm{nt}$ & $\mathrm{P} 1 . \underline{20}, \underline{\mathrm{Ba}}$ & $\mathrm{A}$ \\
N.72697 & $\mathrm{B}$ & 4,7 & $\mathrm{nt}$ & $\mathrm{P} 1 . \underline{7 \mathrm{~b}}, \underline{13 \mathrm{a}}$ & $\mathrm{I}$ \\
N.96697 & $\mathrm{B}$ & 4,7 & $\mathrm{nt}$ & $\mathrm{P} 1 . \underline{7 b}, \underline{13 \mathrm{a}}$ & $\mathrm{A}$ \\
N.118797 & $\mathrm{B}$ & 4,7 & $\mathrm{nt}$ & $\mathrm{P} 1 . \underline{\mathrm{E}}, \underline{15 \mathrm{a}}$ & $\mathrm{A}$ \\
N.120897 & $\mathrm{B}$ & 4,7 & $\mathrm{nt}$ & $\mathrm{P} 1 . \underline{\mathrm{E}}, \underline{15 \mathrm{a}}$ & $\mathrm{A}$ \\
\hline
\end{tabular}

regions of the porA gene, (U86 and R435 for VR1 region; F435 and R773 for VR2 region) ${ }^{13}$. PCR and DNA sequencing techniques were performed as described previously ${ }^{12}$. DNA sequences obtained from these reactions were aligned, edited and the consensus sequence determined with the University of Wisconsin Genetics Computer Group (GCG) ${ }^{3}$. Predicted amino acid sequence was obtained by translating nucleotide sequences.

Nucleotide sequence accession numbers. The scheme of SACCHI et al. ${ }^{12}$ for PorB and PorA VR typing was used to assign names to novel variable regions peptide sequences. The sequences of por $B$ genes obtained during this study have been submitted to GenBank and assigned the accession numbers listed in Table 3.

\section{RESULTS AND DISCUSSION}

In Brazil, during 1997, among the 630 meningococcal serogroup B isolates, $512(81 \%)$ were identified as serotype 4. Serotyping using the expanded panel of serotype-defining mAbs divided this group of strains into five phenotypic groups, $4 ; 4,1 ; 4,7 ; 4,10$; and 4,21 . The most prevalent type was displayed by $489 \mathrm{~B}: 4,7$ strains. Serosubtypes P1.15 (B:4,7:P1.15) and P1.7,1 (B:4,7:P1.7,1) were the most common, together representing $75 \%$ of all group $B$ meningococci isolated during the period (Table 1). The second most prevalent type was B:4,10 encompassing 20 strains; their prevalent serosubtype was P1.9 (11 strains or $55 \%$ of B:4,10).

The genetic diversity among the 105 Neisseria strains from our collection was further investigated by RFLP. The diversity of RFLP patterns of the rRNA genes by using ClaI or EcoRV endonucleases, divided those strains into ten and five different patterns, respectively. When banding patterns for the two restriction endonucleases were combined, 12 unique ribotypes were obtained designed A to L (Table 2).

Strains expressing PorB epitope 4 were divided into nine genetically distinct groups, ribotypes A through I (Fig. 1). Ribotypes with more than $85 \%$ identical bands were combined into groups: Rb Group-1 composed of ribotypes $\mathrm{C}$ and $\mathrm{D}$ (B:4,10 phenotype), and Rb Group-2 composed of ribotypes A, B, E, F, and I (B:4,7 phenotype). Comparison of the Rbs of these two groups showed about $75 \%$ identical RFLP band patterns. The B:4,1 and B:4,21 strains (one isolate of each) displayed distinct ribotypes (Fig.1). Genes coding for rRNA are highly conserved and most bacteria have multiple ribosomal operons. The restriction pattern of rRNA genes carry useful taxonomic information, thus, probing permits inter-species and intra-species discrimination ${ }^{5}$, as showed by the out group (ribotypes J - L) (Fig. 1).

The characterization of a second PorB epitope divided the serotype 4 strains into subgroups. These subgroups were composed by genetically related strains as determined by ribotyping. These results suggest that the characterization of an additional PorB epitope can improve the correlation between phenotypic and genotypic characteristics of meningococcal B strains.

Among the $630 N$. meningitidis serogroup B strains isolated during 1997, a total of eight strains expressing PorB epitopes $4(n=1)$ or $7(n$ $=6)$ or $10(n=1)$ had a second VR epitope which did not react with our
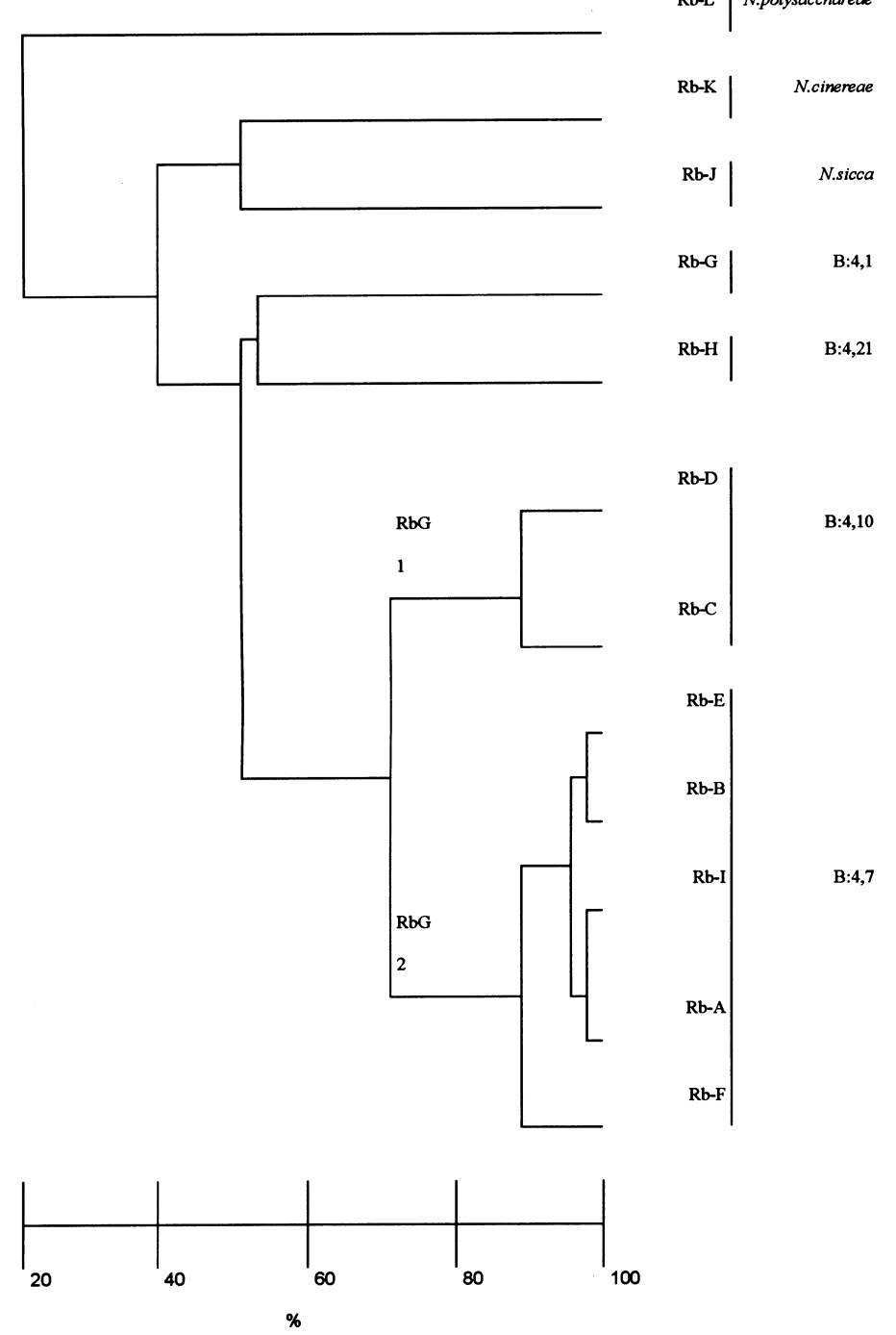

Fig.1 - Dendrogram showing strain relatedness among Rbs of Neisseria determined by ribotyping. 
serotype-defining mAb panel. DNA sequence of the porB gene VRs was used to determine these PorB VR amino acid sequences. The predicted PorB VR1 and VR3 sequences on six of those eight strains were variants of the epitopes 4 and 7 families, explaining the lack of reactivity with the corresponding mAbs (Table 3 ). The lack of mAb reactivity for the other two strains could be explained by the presence of a new PorB VR1 in strain N.5697 and a complete deletion of PorB VR1 in strain N.103197 (Table 3).

Among the 512 meningococcal serogroup B expressing the PorB epitope 4, nine strains did not react with our serosubtype-defining mAb panel. DNA sequence was used to characterize the VRs of PorA protein. Our PorA VR typing results revealed that there were at least 2 reasons that could explain the inability of the traditional serosubtyping method to characterize some of the strains. First, an incomplete set of mAbs was used for serosubtyping our isolates. The PorA VR typing results showed that three of our isolates were P1.13a and one was P1.20 for which serosubtype-defining mAbs exist. However, these mAbs were not available at the time the study was carried out, and thus they were not included in our panel of serosubtyping mAbs. Using these mAbs, we would have been able to characterize those VR epitopes in four additional strains.

The second reason may be due to the high degree of amino acid sequence variation that we found in PorA VR1 and VR2 regions. Among these isolates, ten PorA VR sequences were identified, five in the VR1 (VR1-E, -Eb, -Eg, -5b and -7b) and five sequences in the VR 2 (VR2-A, - Ba, $-10 \mathrm{a},-10 \mathrm{i},-15 \mathrm{a})$, Table 4.

During the last few years, the PorA protein became the most important meningococcal serogroup B vaccine component due to its capacity to induce high levels of bactericidal antibodies. For this reason, the characterization of PorB proteins is now mainly used as an epidemiological marker. In a previous study the expanded panel of mAbs permitted a reduction in the number of non-serotypeable strains ${ }^{12}$. However, PorB epitope characterization by using novel serotype-defining $\mathrm{mAbs}$ is only useful if this increase in sensitivity is also followed by an increase in the correlation with genotype-based methods. For this reason the present work reevaluates this correlation, comparing results obtained by serotyping with an expanded $\mathrm{mAb}$ panel and by ribotyping.

Until recently, only one of the four PorB VR epitopes could be characterized by using the traditional set of serotype-defining mAbs. Our results show that the characterization of more than one PorB VR epitope on the same meningococcal strain can increase the correlation between phenotype-based and genotype-based methods. The expanded set of serotype-defining mAbs increased the sensitivity of the method making it possible to access information previously available only by analysis of predicted PorB protein from porB gene sequencing (PorB VR typing).

From the public health point of view, and in light of our extensive experience with laboratory typing methods, serotyping is an important tool for $N$. meningitidis epidemiology. For economic and other reasons, serotyping will continue to be the main method of typing $N$. meningitidis serogroup B in developing countries for many years to come. Serotyping is useful for routine purposes, and will also provide epidemiological information as long as a complete set of mAbs is used.

\section{RESUMO \\ Relação genética entre cepas de Neisseria meningitidis sorogrupo B sorotipo 4}

Nós comparamos os resultados obtidos pela sorotipagem usando um painel de anticorpos monoclonais $(\mathrm{mAb})$ ao qual se incluíam os mAbs 7 e 10, com os resultados obtidos pelo RFLP do gene $r$ RNA (ribotipagem). O propósito deste estudo foi avaliar a correlação entre os métodos fenotípico e genotípico de tipagem de $N$. meningitidis. Os ribotipos obtidos usando as endonucleases de restrição ClaI e EcoRV foram hábeis em dividir as cepas em sete e dois diferentes perfis de restrição, respectivamente. A caracterização adicional de epítopos na proteína PorB melhorou a correlação entre os dois métodos de tipagem de N. meningitidis.

\section{ACKNOWLEDGMENTS}

We gratefully acknowledge the constructive criticism of Mary E. Brandt.

\section{REFERENCES}

1. ALTWEGG, M.; HICKMAN-BRENNER, F.W. \& FARMER III, J.J. - Ribosomal RNA gene restriction pattern provide increased sensivity for typing Salmonella typhi strain. J. infect. Dis., 160: 145-149, 1989.

2. BASH, M.C.; LESIAK, K.B.; BANKS, S.D. \& FRASCH, C.E. - Analysis of Neisseria meningitidis class 3 outer membrane protein gene variable regions and type identification using genetic techniques. Infect. Immun., 63: 1484-1490, 1995.

3. DEVEREUX, J.P.; HAEBERLI, P. \& SMITHIES, O. - A comprehensive set of sequence analysis programs for the VAX. Nucleic Acids Res., 12: 387-395, 1984.

4. FEAVERS, I.M.; SUKER, J.; MCKENNA, A.J.; HEATH, A.B. \& MAIDEN, M.C.J. Molecular analysis of the serotyping antigens of Neisseria meningitidis. Infect. Immun., 60: 3620-3629, 1992.

5. GRIMONT, F. \& GRIMONT, P.A.D. - Ribosomal ribonucleic acid gene restriction patterns as potential taxonomic tools. Ann. Inst. Pasteur Microbiol., 137B: 165-175, 1986.

6. MAIDEN, M.C.; SUKER, J.; MCKENNA, A.J.; BYGRAVES, J.A. \& FEAVERS, I.M. - Comparison of the class 1 outer membrane proteins of eight serological reference strains of Neisseria meningitidis. Molec. Microbiol., 5: 727-736, 1991.

7. McGUINNESS, B.T.; BARLOW, A.K.; CLARKE, I.N. et al. - Deduced amino acid sequences of class 1 protein (PorA) from 3 strains of Neisseria meningitidis. Synthetic peptides define the epitopes responsible for serosubtype specificity. J. exp. Med., 171: $1871-1882,1990$

8. McGUINNESS, B.T.; LAMBDEN, P.R. \& HECKELS, J.E. - Class 1 outer membrane protein of Neisseria meningitidis: epitope analysis of the antigenic diversity between strains, implications for subtype definition and molecular epidemiology. Molec. Microbiol., 7: 505-514, 1993.

9. SACCHI, C.T.; PESSOA, L.L.; RAMOS, S.R. et al. - Ongoing group B Neisseria meningitidis epidemic in São Paulo, Brazil, due to increased prevalence of a single clone of the ET-5 complex. J. clin. Microbiol., 30: 1734-1738, 1992.

10. SACCHI, C.T.; TONDELLA, M.L.C.; GORLA, M.C.O. et al. - Genetic structure of Neisseria meningitidis serogroup C epidemic strains in South Brazil. Rev. Inst. Med. trop. S. Paulo, 37: 281-289, 1995. 
11. SACCHI, C.T.; LEMOS, A.P.S.; CAMARGO, M.C.C. et al. - Meningococcal disease caused by Neisseria meningitidis serogroup B serotype 4 in São Paulo, Brazil, 1990 to 1996. Rev. Inst. Med. trop. S. Paulo, 40: 65-70, 1998.

12. SACCHI, C.T.; LEMOS, A.P.S.; WHITNEY, A.M. et al. - Correlation between serological and sequencing analyses of the PorB outer membrane protein in the Neisseria meningitidis serotyping system. Clin. diagn. Lab. Immun., 5: 348-354, 1998.

13. SACCHI, C.T.; LEMOS, A.P.S.; BRANDT, M.E. et al. - Proposed standardization of Neisseria meningitidis PorA variable-region typing nomenclature. Clin. diagn. Lab. Immun., 5: 845-855, 1998.

14. TONDELLA, M.L.C.; SACCHI, C.T. \& NEVES, B.C. - Ribotyping as an additional molecular marker of Neisseria meningitidis serogroup B epidemic strains. J. clin. Microbiol., 32: 2745-2748, 1994.
15. VAN DER LEY, P.; HECKELS, J.E.; VIRJI, M.; HOOGERHOUT, P. \& POOLMAN, J.T. - Topology of outer membrane porins in pathogenic Neisseria spp. Infect. Immun., 59: 2963-2971, 1991.

16. WARD, M.J.; LAMBDEN, P.R. \& HECKELS, J.E. - Sequence analysis and relationships between meningococcal class 3 serotype proteins and other porins from pathogenic and non-pathogenic Neisseria species. FEMS Microbiol. Lett., 73: 283-289, 1992.

17. WEDEGE, E.; HOIBY, E.A.; ROSENQVIST, E. \& FROHOLM, L.O. - Serotyping and subtyping of Neisseria meningitidis isolates by co-agglutination, dot-blotting and ELISA. J. med. Microbiol., 31: 195-201, 1990.

18. ZAPATA, G.A.; VANN, W.F.; RUBINSTEIN, Y. \& FRASCH, C.E. - Identification of variable region differences in Neisseria meningitidis class 3 protein sequences among five group B serotypes. Molec. Microbiol., 6: 3493-3499, 1992.

Received: 26 October 2000

Accepted: 01 February 2001 